\title{
Effect of Separator Thickness and Preheating Temperature on the Development of Microwave Processed Composite Clads
}

\author{
Sarbjeet Kaushal*, Dheeraj Gupta and Hiralal Bhowmick \\ Department of Mechanical Engineering, Thapar Institute of Engineering and Technology, India \\ *Corresponding author: Sarbjeet Kaushal, Department of Mechanical Engineering, Punjab, India \\ Submission: 侮 December 18, 2017; Published: 械 December 22, 2017
}

\begin{abstract}
Microwave cladding has emerged as a noble surface modification method. Microwave cladding uses the principle of microwave hybrid heating in which a suitable separator material is used. In the present work, Ni/wc based composite clads were developed on austenitic steel through microwave heating route at $900 \mathrm{~W}$ and $2.45 \mathrm{GHz}$. The effect of various preheating temperature of raw powders and different thickness of separator on the development of composite clads have been analyzed. It was observed that the minimum processing time for development of clad was achieved at $1 \mathrm{~mm}$ thickness of susceptor and $180{ }^{\circ} \mathrm{C}$ of preheating temperature.
\end{abstract}

Keywords: Separator; Microwave cladding; Hybrid heating

\section{Introduction}

Microwave cladding is a versatile and energy efficient surface modification technique. Microwave cladding utilizes the microwave energy as the heating source for melting of clad powder. However, the behavior of different material towards microwaves depends upon their skin depth [1]. The skin depth of the material can be enhanced by using microwave hybrid heating $(\mathrm{MHH})$ principle [2]. The MHH method uses the susceptor particles (charcoal powder) having good dielectric strength, which initially absorb the microwaves and convert into heat energy. The susceptor particles are placed on the composite powder layer. To prevent any type of contamination of susceptor particles and composite powder particles, a thin separator sheet of alumina is used. In the present work, separator of three different thickness $1 \mathrm{~mm}, 1.5 \mathrm{~mm}, 2 \mathrm{~mm}$ and $2.5 \mathrm{~mm}$ were used and their effect on the processing time of development of composite clads were analyzed. Apart from this, the effect of preheating temperature of raw clad powder on the processing time has also been analyzed and discussed in the present study.

\section{Materials and Methods}

In the present research, Ni-based metallic powder and WC8Co based ceramic powder has been selected as cladding powders. The powders were premixed in a mechanical mixture to obtain the proportion of $\mathrm{Ni}+20 \%$ wc $8 \mathrm{co}$. Prior to placing of powder layer on the austenitic stainless steel substrate (SS-316 L), the composite powder was preheated at different temperatures starting from $20^{\circ} \mathrm{C}$ to $180^{\circ} \mathrm{C}$ in the step size of $20^{\circ} \mathrm{C}$. The preheated composite powder layer was placed on SS-316 L substrate and the development of cladding is carried out inside a microwave applicator using microwave hybrid heating principle [3]. The developed clads were characterized by scanning electron microscopy (SEM). The effect of preheating temperature and separator thickness on the processing times were analyzed.

\section{Results and Discussion}
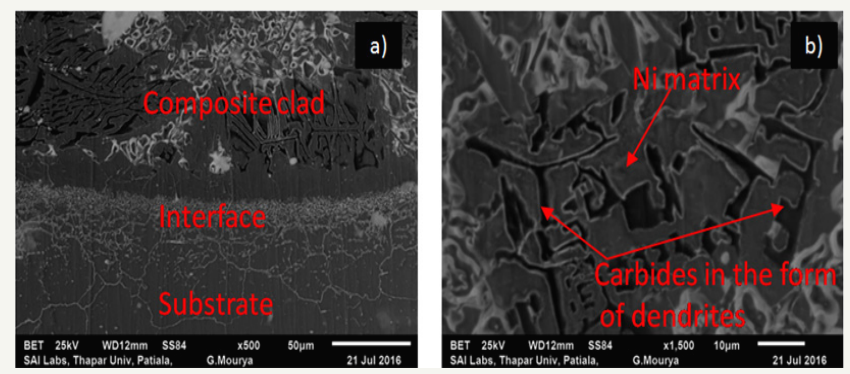

Figure 1: BSE image showing

1a: Transverse section of composite clad

1b: Zoomed image of clad region

The backscattered electronic image of a transverse section of composite clad is shown in Figure 1a. It was observed that a wavy 
interface was present between clad and substrate region. Further, the zoomed image of the clad section is shown in Figure 1b, which revealed that the $\mathrm{WC}$ particles are randomly dispersed in the $\mathrm{Ni}$ matrix in the form of dendritic structure. The effect of preheating temperature and separator thickness on the processing time of composite clads was plotted in Figure 2. It was observed that, the minimum processing time for clad formation occurred at $180{ }^{\circ} \mathrm{C}$ preheating temperature and $1 \mathrm{~mm}$ of separator thickness.
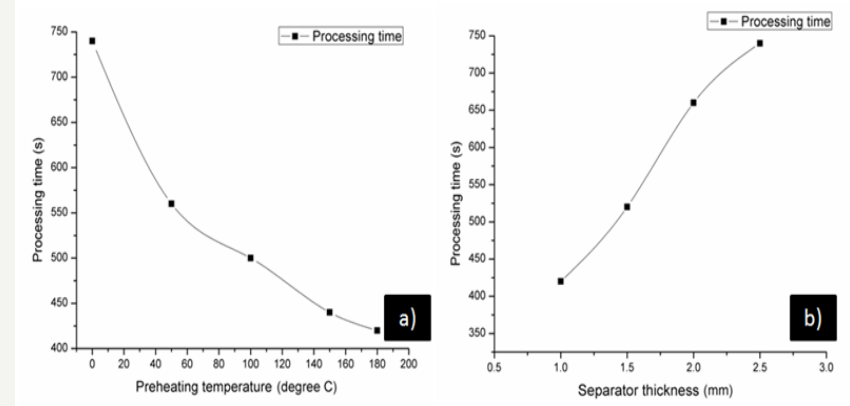

Figure 2: (a) Preheating temperature vs processing time graph, (b) Separator thickness vs processing time graph.

\section{Conclusion}

In the present research, the $\mathrm{Ni} / \mathrm{wc}$ based composite clads was successfully developed on SS-316 L substrate through microwave heating. The wc particles were randomly distributed in the $\mathrm{Ni}$ matrix. The minimum processing time of development of cladding was optimized and it was at $180^{\circ} \mathrm{C}$ preheating temperature and at $1 \mathrm{~mm}$ of separator thickness.

\section{References}

1. Gupta D, Sharma AK (2011) Development and microstructural characterization of microwave cladding on austenitic stainless steel. Surf Coatings Technol 205(21-22): 5147-5155.

2. Kaushal S, Gupta D, Bhowmick HL (2017) Investigation of dry sliding wear behavior of composite cladding developed through microwave heating. J Tribol 139(4): 041603-041609.

3. Kaushal S, Sirohi V, Gupta D, Bhowmick HL, Singh S (2015) Processing and characterization of composite cladding through microwave heating on martensitic steel. Mat Dsgn and Appl 232(1): 80-86. 